\title{
Article \\ Calcium Hydroxyapatite: A Highly Stable and Selective Solid Catalyst for Glycerol Polymerization
}

\author{
Negisa Ebadipour (D), Sébastien Paul (D), Benjamin Katryniok and Franck Dumeignil *(D) \\ Univ. Lille, CNRS, Centrale Lille, Univ. Artois, UMR 8181-UCCS-Unité de Catalyse et Chimie du Solide, \\ F-59000 Lille, France; negisa.ebadi-pour@centralelille.fr (N.E.); sebastien.paul@centralelille.fr (S.P.); \\ benjamin.katryniok@centralelille.fr (B.K.) \\ * Correspondence: franck.dumeignil@univ-lille.fr; Tel.: +33-(0)3-20-43-45-38
}

Citation: Ebadipour, N.; Paul, S.; Katryniok, B.; Dumeignil, F. Calcium Hydroxyapatite: A Highly Stable and Selective Solid Catalyst for Glycerol Polymerization. Catalysts 2021, 11, 1247. https://doi.org/10.3390/ catal11101247

Academic Editors: Francesco Ruffo and Roberto Esposito

Received: 28 September 2021

Accepted: 12 October 2021

Published: 17 October 2021

Publisher's Note: MDPI stays neutral with regard to jurisdictional claims in published maps and institutional affiliations.

Copyright: (c) 2021 by the authors. Licensee MDPI, Basel, Switzerland. This article is an open access article distributed under the terms and conditions of the Creative Commons Attribution (CC BY) license (https:/ / creativecommons.org/licenses/by/ $4.0 /)$.

\begin{abstract}
Calcium-based catalysts are of high interest for glycerol polymerization due to their high catalytic activity and large availability. However, their poor stability under reaction conditions is an issue. In the present study, we investigated the stability and catalytic activity of Ca-hydroxyapatites (HAps) as one of the most abundant Ca-source in nature. A stochiometric, Ca-deficient and Ca-rich HAps were synthesized and tested as catalysts in the glycerol polymerization reaction. Deficient and stochiometric HAps exhibited a remarkable $100 \%$ selectivity to triglycerol at $15 \%$ of glycerol conversion at $245^{\circ} \mathrm{C}$ after $8 \mathrm{~h}$ of reaction in the presence of $0.5 \mathrm{~mol} \%$ of catalyst. Moreover, under the same reaction conditions, Ca-rich HAp showed a high selectivity $(88 \%)$ to di- and triglycerol at a glycerol conversion of $27 \%$. Most importantly, these catalysts were unexpectedly stable towards leaching under the reaction conditions based on the ICP-OES results. However, based on the catalytic tests and characterization analysis performed by XRD, XPS, IR, TGA-DSC and ICP-OES, we found that HAps can be deactivated by the presence of the reaction products themselves, i.e., water and polymers.
\end{abstract}

Keywords: hydroxyapatite; ca-based catalyst; stability; polyglycerol

\section{Introduction}

Polyglycerols (PGs) are very interesting polyols with a wide range of structures and applications, particularly in the cosmetics, biomedical, and food sectors. PGs are watersoluble, biocompatible, and highly functional materials. Currently, 52\% of the PGs market demand is occupied by the short-chain PGs, including PG2 and PG3 (PG2-3) [1].

In the last few years, attention has been paid to alkaline-based catalysts such as earth metal oxides [2-4], Ca/La mixed oxides [5,6] and alkaline-modified zeolite [7,8] due to their higher selectivity to PGs compared to acid catalysts [5,9-11]. Among the alkaline catalysts, $\mathrm{CaO}$-based catalysts such as $\mathrm{CaO}[2,12]$, supported $\mathrm{CaO}$ on $\mathrm{CNF}[3]$, dolomite (CaO-MgO mixed oxides) [4], and calcined eggshell [13] have shown high catalytic performances with no acrolein formation [9]. Moreover, considering the wide availability of $\mathrm{Ca}$, its low cost, and its absence of toxicity in the case of catalyst leaching into the media, Ca-based catalysts can be especially considered promising for glycerol polymerization reactions [9,12]. However, such catalysts usually exhibit a moderate selectivity to PG2-3. For instance, Kirby et al. [3] reported a 45\% selectivity to PG2-3 at full glycerol conversion in the presence of $\mathrm{CaO} / \mathrm{CNF}$. Barros et al. [4] also reported 55\% selectivity to PG2-3 at glycerol conversion of $90 \%$ in the presence of dolomite $\left(\mathrm{CaCO}_{3} \cdot \mathrm{MgCO}_{3}\right)$.

Furthermore, the heterogenous catalysts were generally unstable under polymerization reaction conditions, which induced totally or partially homogeneously-catalyzed conditions due to the activity of leached species. For Ca-based catalysts, this homogenous contribution has been attributed by many groups to the action of colloidal $\mathrm{Ca}(\mathrm{OH})_{2}$ and $\mathrm{Ca}^{2+}[2,7,13-15]$. For instance, Barros et al. [13] reported that $49 \%$ of solid CaO-egg shell became homogeneous (i.e., dissolved in the reaction medium under the form of $\mathrm{Ca}^{2+}$ ) 
after $24 \mathrm{~h}$ of reaction. Thus, the homogeneous contribution in the PG reaction is still an unsolved problem.

Many types of Ca-rich compounds, particularly those derived from organic wastes such as waste fish scales and animal bones, have been successfully used as catalysts [16-19]. In fact, the mineral phase of bones consists of non-stoichiometric calcium hydroxyapatite (HAp). Hydroxyapatites are widely used in biomedical applications due to their similarity - from a crystallographic point of view and in terms of chemical composition, with human hard tissues such as bones and teeth [20]. Furthermore, due to their interesting properties such as high thermal stability, very limited water solubility, and insolubility in alkaline solutions [21], HAps have also found many applications in catalysis [16-19,22-24], protein separation [25], and in waste-water and soil treatment [21]. Hence, we decided to study heterogeneous catalysts based on Ca hydroxyapatite for the glycerol polymerization reaction due to these advantages.

Calcium hydroxyapatite can be present in various forms;

I. Stochiometric HAp with formula $\mathrm{Ca}_{10}\left(\mathrm{PO}_{4}\right)_{6}(\mathrm{OH})_{2}$ with a Ca/P molar ratio of 1.67.

II. Deficient HAp (non-stoichiometric) hydroxyapatites with $\mathrm{Ca} / \mathrm{P}<1.67$, which are generally represented by the formula $\mathrm{Ca}_{10-x}\left(\mathrm{PO}_{4}\right)_{6-x}\left(\mathrm{HPO}_{4}\right)_{x}(\mathrm{OH})_{2-x}$ with $0<x<1$. Outside this compositional range, the compounds can change to multiphasic mixtures including $\beta$-tricalcium phosphate $\left(\beta\right.$-TCP) with a formula of $\mathrm{Ca}_{3}\left(\mathrm{PO}_{4}\right)_{2}$ with $\mathrm{Ca} / \mathrm{P}$ ratio of 1.5; octacalcium phosphate (OCP) $\left(\mathrm{Ca}_{8} \mathrm{H}_{2}\left(\mathrm{PO}_{4}\right)_{6} \cdot x \mathrm{H}_{2} \mathrm{O}\right)$ with a $\mathrm{Ca} / \mathrm{P}$ ratio of 1.33 , calcium hydrogen phosphate $\left(\mathrm{CaHPO}_{4}\right)$ with a $\mathrm{Ca} / \mathrm{P}$ ratio of 1 and calcium pyrophosphate (DCP) $\left(\beta-\mathrm{Ca}_{2} \mathrm{P}_{2} \mathrm{O}_{7}\right)$ with a $\mathrm{Ca} / \mathrm{P}$ ratio of 1 [26-28].

III. Over-stoichiometric HAp or rich HAp (HAp-R) with a Ca/P molar ratio above 1.67. Generally, the excess of $\mathrm{Ca}$ in HAp-R could lead to the formation of $\mathrm{CaO}$ or $\mathrm{Ca}(\mathrm{OH})_{2}$ on the HAp surface [26].

Among the various HAp groups mentioned above, biological HAp has been studied for transesterification reactions by several groups [17,19]. For instance, Farooq et al. [17] studied HAp derived from waste chicken bones as a heterogeneous catalyst utilized in the transesterification reaction of waste cooking oil for biodiesel production. They reported a biodiesel yield of ca. $89 \%$ at $5 \mathrm{wt} . \%$ of catalyst loading, at a temperature of $65{ }^{\circ} \mathrm{C}$, and a reaction time of $4 \mathrm{~h}$. Furthermore, the catalyst was reused for four cycles with a biodiesel yield of 79\%, where the recovered catalyst was calcined after each reaction. The performance decrease observed after the deactivation of the catalyst explained each cycle by deposition of unreacted oil, biodiesel, or glycerol on the active sites at the surface of the catalyst.

With respect to these results, HAp could be a suitable catalyst for glycerol polymerization, a liquid phase condensation reaction at high temperatures. To the best of our knowledge, no study has been reported so far on the catalytic activity of HAps in the glycerol polymerization reaction. Therefore, based on the literature review, we decided to develop new catalysts based on calcium hydroxyapatite, which were assumed to act heterogeneously in the glycerol polymerization reaction.

Thus, we developed several Ca-based HAps catalysts with various $\mathrm{Ca} / \mathrm{P}$ ratios and studied their catalytic performances on the glycerol polymerization reaction in this work. Based on the catalyst characterizations and the catalytic activities, the catalyst deactivation mechanism has also been studied.

\section{Results}

\subsection{Catalytic Performances}

Herein, three Ca-based HAp catalysts have been tested: a stoichiometric HAp (HAp-S) with a theoretical $\mathrm{Ca} / \mathrm{P}$ molar ratio of 1.67 , a deficient HAp (HAp-D) with a theoretical $\mathrm{Ca} / \mathrm{P}$ molar ratio of 1.45 and a rich-HAp $(\mathrm{HAp}-\mathrm{R})$ with a theoretical $\mathrm{Ca} / \mathrm{P}$ molar ratio of 1.94. The catalytic performances of these three catalysts were evaluated at $245^{\circ} \mathrm{C}$ in the presence of $0.5 \mathrm{~mol} . \%$ of catalyst for $8 \mathrm{~h}$ reaction, as shown in Figure 1 (left). 
The results showed that HAp-S and HAp-D exhibited the same catalytic performances: $15 \%$ glycerol conversion with a full selectivity to PG3. In fact, these catalysts are highly selective to one molecule, which has been identified to be cyclic-PG3 by ESI-MS (Figure 2a,b). Surprisingly, the conversion of HAp-S and HAp-D did not increase when the reaction time was prolonged to $22 \mathrm{~h}$ (Figure 1 right).

For the Ca-rich hydroxyapatite (HAp-R), a glycerol conversion of $27 \%$ with high selectivity to PG2-3 (88\%) was also observed after $8 \mathrm{~h}$ of reaction. Moreover, in contrast to HAp-S, the glycerol conversion increased to $42 \%$ with $77 \%$ of PG2-3 selectivity when the reaction was carried out for $22 \mathrm{~h}$ under the same reaction conditions (Figure $1 \mathrm{right}$ ). This increase in catalytic performances might also be attributed to the Ca leaching $(0.37 \mathrm{mg} / \mathrm{g})$ into the reaction medium, which could cause a partially homogeneous reaction. Furthermore, the HAp-R was also highly selective to linear PG2 and PG3 (as shown in Figure 2c), where the peaks at 189.1 Da and 263.1 Da correspond to linear PG2 and PG3, respectively.

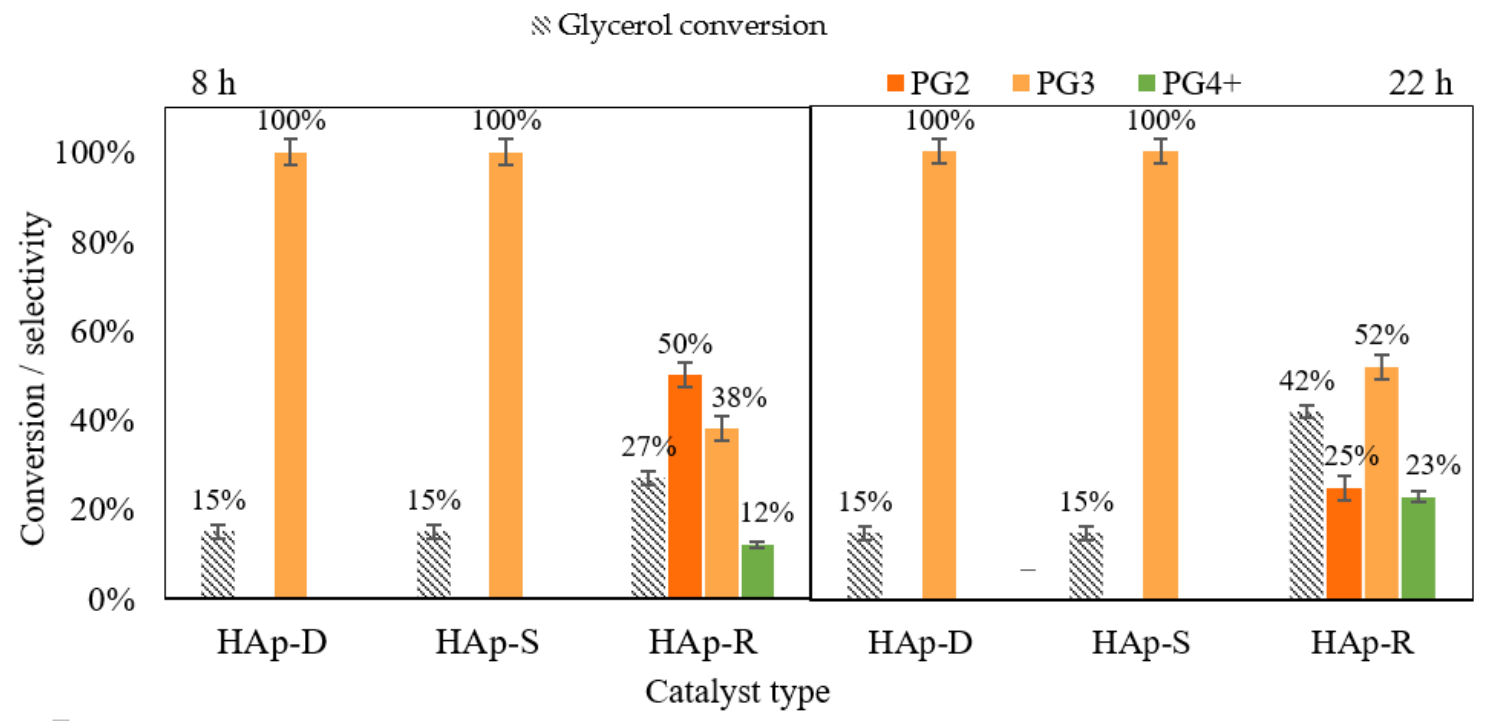

Figure 1. Catalytic activity in the glycerol polymerization reaction of HAp-D, HAp-S, and HAp-R at $245^{\circ} \mathrm{C}$ after $8 \mathrm{~h}$ of reaction (left) and after $22 \mathrm{~h}$ (right).

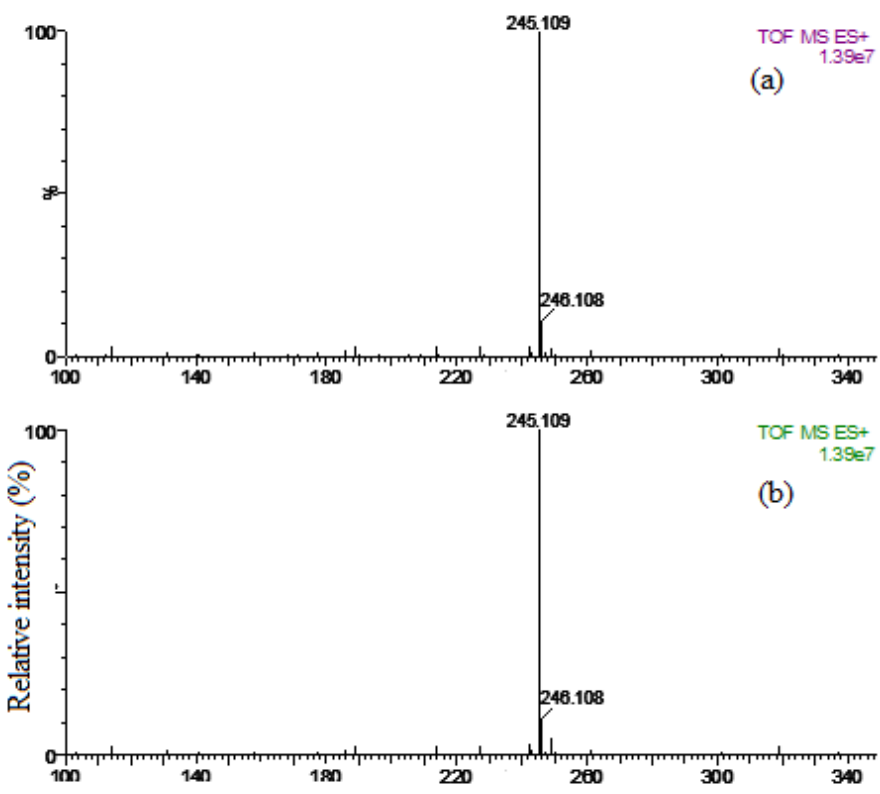

Figure 2. Cont. 


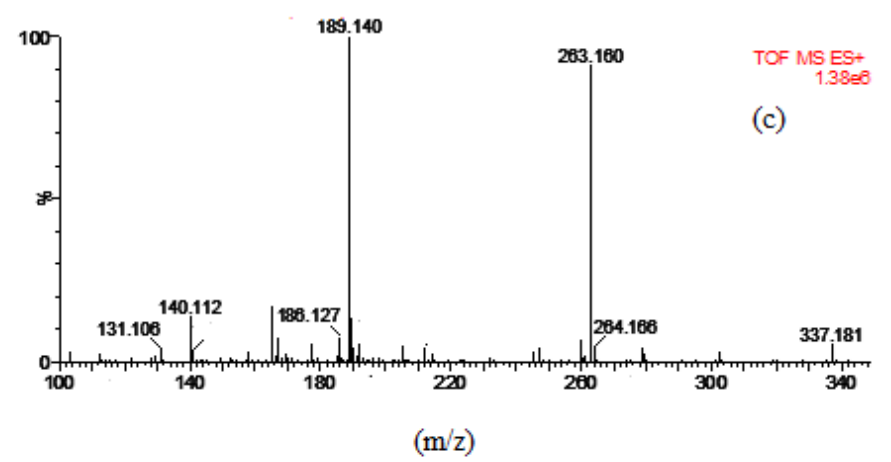

Figure 2. ESI-MS spectra of reaction media when (a) HAp-D, (b) HAp-S, and (c) HAp-R were used as the catalyst at $245^{\circ} \mathrm{C}$ after $8 \mathrm{~h}$ of reaction.

When HAp-D and HAp-S were used as catalysts, low amounts of catalyst leached to the respective reaction media after $8 \mathrm{~h}$ of reaction (namely, 1.8\% for HAp-D and $0.5 \%$ for HAp-S as shown in Table 1). Thus, since no increase in glycerol conversion nor PGs selectivity was observed after $22 \mathrm{~h}$ of reaction time (Figure 1), there is no strong evidence indicating that the catalytic performances were related to any homogeneous catalysis provoked by leached species.

Table 1. Catalytic performances in glycerol polymerization reaction in the presence of $0.5 \mathrm{~mol} \%$ of $\mathrm{CaO}$ and different HAps and percentages of leached $\mathrm{Ca}$ based on the ICP-OES when $0.5 \mathrm{~mol} \%$ of catalysts were used at $245^{\circ} \mathrm{C}$ for $8 \mathrm{~h}$.

\begin{tabular}{cccccc}
\hline Catalyst & $\begin{array}{c}\text { Glycerol } \\
\text { Conversion (\%) }\end{array}$ & $\begin{array}{c}\text { PG2 } \\
\text { Selectivity (\%) }\end{array}$ & $\begin{array}{c}\text { PG3 } \\
\text { Selectivity (\%) }\end{array}$ & $\begin{array}{c}\text { PG4+ } \\
\text { Selectivity (\%) }\end{array}$ & Leached Ca. (\%) \\
\hline CaO & 36 & 8 & 22 & 70 & 100 \\
HAp-D & 15 & 0 & 100 & 0 & 1.8 \\
HAp-S & 15 & 0 & 100 & 0 & 0.5 \\
HAp-R & 27 & 50 & 38 & 12 & 3.4 \\
\hline
\end{tabular}

The quantity of calcium leached in the reaction medium (Table 1) was also very low in the presence of HAp-R (3.4\%) in the same reaction conditions. In contrast, $\mathrm{CaO}$, as a typical Ca-based catalyst, became totally soluble after $1 \mathrm{~h}$ of reaction. Thus, HAp-based catalysts are highly stable compared to $\mathrm{CaO}$.

The catalytic results obtained so far showed that among several HAp-based catalysts, the most promising one is HAp-S, both in terms of selectivity to PG3 and stability (very low Ca leaching). Hence, hereafter, the recycling of this catalyst was studied.

\subsection{Activity of Recycled Catalyst}

The catalytic performance of spent catalysts obtained from HAp-S was assessed upon recovery/reutilization under the same reaction conditions. The spent catalyst was washed with two different solvents: (1) water, labeled HAp-W or (2) EtOH, labeled HAp-Et.

Using ethanol to wash the used catalyst, it was shown that the recovered catalyst from the 1st run reaction, HAp-Et-1, had a glycerol conversion of $15 \%$, similar to that of the fresh HAp-S catalyst. Moreover, the spent catalysts, HAp-Et-1 and HAp-Et-2, were successfully reused in the 2nd and 3rd run reactions, without loss in activity (Figure 3). Most importantly, the reused catalyst (HAp-Et-1 and HAp-Et-2) still exhibited 100\% selectivity to PG3.

Surprisingly, when the HAp-Et-1 was recalcined prior to the 2nd run reaction, the glycerol conversion decreased to $7 \%$ (HAp-Et-Cal-1). Recalcination of spent catalysts was carried out under static air, which probably caused a change in HAp stoichiometry. This could happen by forming carbonated groups due to the presence of $\mathrm{O}_{2}$ or $\mathrm{CO}_{2}$ in the oven atmosphere. This will be further discussed in Section 3.1. 


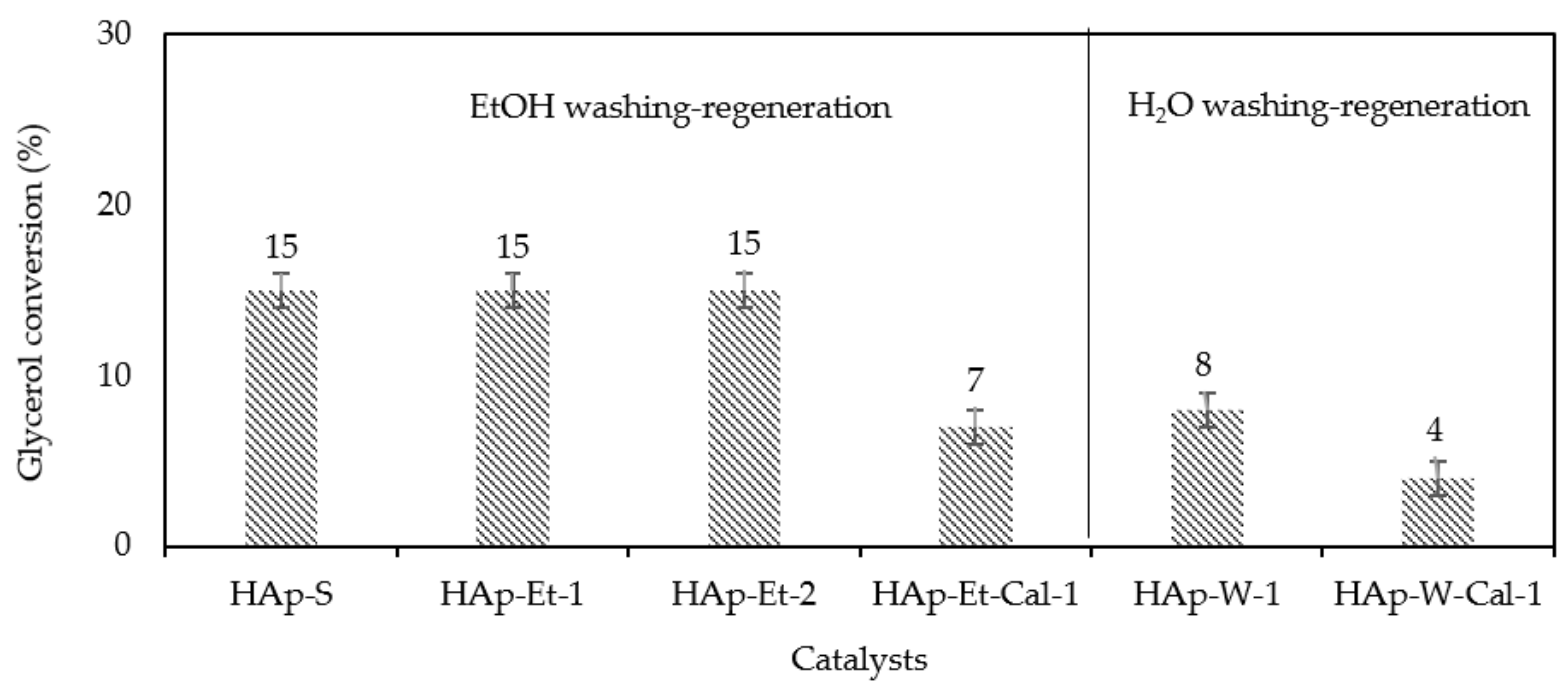

Figure 3. The catalytic activity of fresh HAp-S and recovered catalysts with washing using EtOH or $\mathrm{H}_{2} \mathrm{O}$.

Unlike HAp-Et-1, the used catalyst washed with water (HAp-W-1) showed a lower glycerol conversion of $8 \%$ with a $100 \%$ selectivity to PG3 compared to initial HAp-S (15\% of conversion) (Figure 3). In this case, the decrease in catalytic performance might be due to the formation of a hydrated layer on the catalyst surface that causes a loss of catalyst activity. Moreover, when the recovered catalyst was recalcined prior to the reaction (HAp-W-Cal -1), lower performances than HAp-W-1 were observed (4\% conversion vs. $8 \%$ ), probably because the hydrated layer was removed but $\mathrm{CO}_{2}$ of the calcination atmosphere created carbonated species. Hence, like in the case of HAp-Et-Cal-1, the catalyst recalcination caused some deactivation.

To understand the deactivation phenomenon after water washing, further characterization of spent catalysts was needed, which will be further discussed.

\subsection{Catalysts Characterization}

HAp-D, HAp-S, and HAp-R were characterized using several techniques, including $\mathrm{BET}, \mathrm{XRD}, \mathrm{XPS}, \mathrm{IR}$, and TGA to study the influence of the $\mathrm{Ca} / \mathrm{P}$ ratio on the bulk and surface properties of the catalysts.

\subsubsection{Surface Characterization and Elemental Analysis}

The specific surface area (SSA) of HAp-D, HAp-S, and Hap-R were measured using BET (Table 2). The HAp-S with $70.4 \mathrm{~m}^{2} / \mathrm{g}$ developed a higher SSA than HAp-D and HAp-R with $19.4 \mathrm{~m}^{2} / \mathrm{g}$ and $13.8 \mathrm{~m}^{2} / \mathrm{g}$, respectively.

Table 2. Chemical compositions and surface areas of fresh and reused HAps.

\begin{tabular}{cccccccc}
\hline Catalyst & Name & $\begin{array}{c}\text { BET } \\
\text { Specific Surface } \\
\text { Area }\left(\mathbf{m}^{\mathbf{2}} / \mathbf{g}\right)\end{array}$ & Theoretical Ca/P & $\begin{array}{c}\text { Ca/P } \\
\text { Atomic Ratio } \\
\text { (ICP) }\end{array}$ & $\begin{array}{c}\text { Ca } \\
\text { (wt.\%) }\end{array}$ & $\begin{array}{c}\mathbf{P} \\
\text { (wt.\%) }\end{array}$ & $\begin{array}{c}\mathbf{C} \\
\text { (wt.\%) }\end{array}$ \\
\hline \multirow{3}{*}{ Fresh catalysts } & HAp-D & 19.4 & 1.45 & 1.62 & 36.16 & 17.33 \\
& HAp-S & 70.4 & 1.67 & 1.66 & 36.07 & 16.84 & 0.108 \\
& HAp-R & 13.8 & 1.94 & 1.78 & 38.44 & 17.39 & 0.8 \\
\hline \multirow{5}{*}{ Reused catalysts } & HAp-W-1 & 38.3 & 1.67 & n.d & n.d & n.d & 2.13 \\
& HAp-Et-1 & 36.6 & 1.67 & n.d & n.d & n.d & 1.96 \\
& HAp-Et-2 & 38 & 1.67 & n.d & n.d & n.d & 2.38 \\
& HAp-Et-Cal-1 & 60 & 1.67 & n.d & n.d & n.d & 0.37 \\
\hline
\end{tabular}

${ }^{*}$ n.d.: Not determined. 
Moreover, the ICP analysis of the catalysts showed that the atomic $\mathrm{Ca} / \mathrm{P}$ ratios of bulk HAp-S, HAp-D, and HAp-R were 1.66, 1.62, and 1.78, respectively, with ca. $36 \mathrm{wt} . \%, 36 \mathrm{wt} . \%$, and $38 \mathrm{wt} . \%$ of calcium, respectively (Table 2$)$. The difference between the experimental and the theoretical $\mathrm{Ca} / \mathrm{P}$ atomic ratios for HAp-D (Table 2) suggests that no other apatite such as $\beta$-tricalcium phosphate, octacalcium phosphate, or calcium pyrophosphate was formed.

In addition, $C$ analysis showed the presence of some carbon in HAp-D, HAp-S, and $\mathrm{HAp}-\mathrm{R}$. The presence of carbon suggests that some atmospheric $\mathrm{CO}_{2}$ was absorbed during the synthesis process, as already reported in the literature $[26,27,29]$. However, since the HAps were calcinated at $700{ }^{\circ} \mathrm{C}$, this result suggests that only a partial release of $\mathrm{CO}_{2}$ could occur at this temperature level.

For the used catalysts washed with EtOH, the BET analysis showed a decrease in the surface area $\left(36.6 \mathrm{~m}^{2} / \mathrm{g}\right.$ for HAp-Et-1 and $38 \mathrm{~m}^{2} / \mathrm{g}$ for HAp-Et-2) compared to HAp-S $\left(73.7 \mathrm{~m}^{2} / \mathrm{g}\right)$. The $\mathrm{C}$ content was also increased for HAp-Et-1 (1.96 wt.\%) and HAp-Et-2 (2.38 wt.\%) compared to HAp-S (0.11 wt.\%) as shown in Table 2. These results suggest that the carbon deposition caused a decrease in the specific surface area of the recovered catalysts. However, it had no effect on its performance. Moreover, the recalcination of catalyst partially removed the $\mathrm{C}$ in HAp-Et-Cal-1, as expected. However, the higher amount of carbon in HAp-W-1 compared to HAp-Et-1 (2.13 wt.\% vs 1.96 wt.\%) confirmed that ethanol was more efficient than water to remove adsorbed species.

\subsubsection{XRD}

X-ray diffractograms of HAp-S, HAp-D, and HAp-R are presented in Figure 4(a-c). The characteristic peaks of calcium hydroxyapatite (PDF 04-014-8416) were observed for all these HAps.
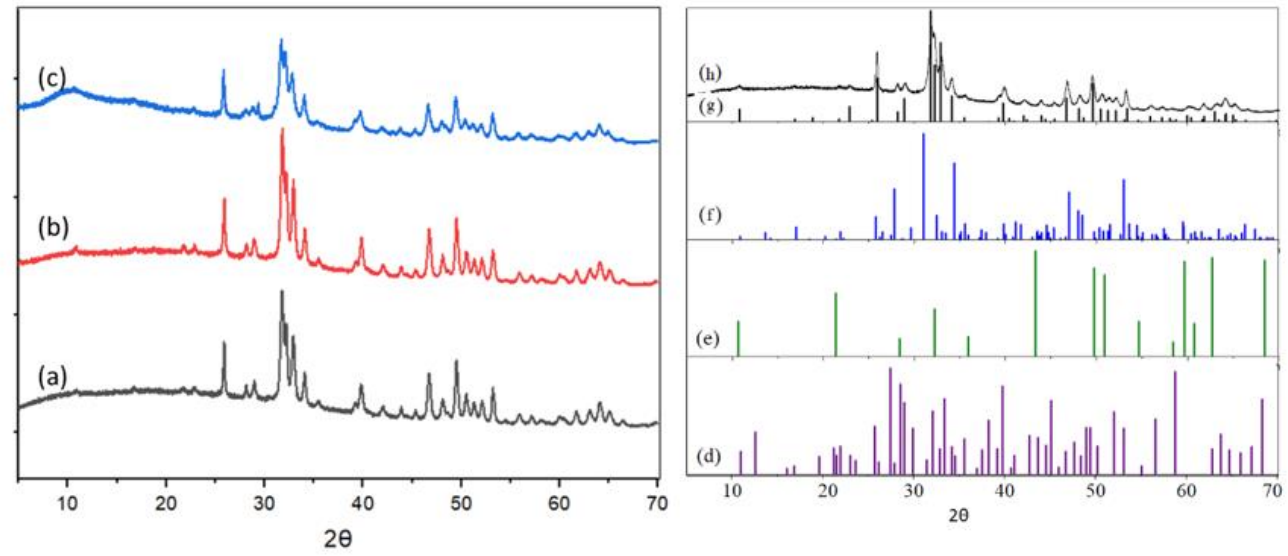

Figure 4. XRD diffractograms of (a) HAp-D, (b) HAp-S and (c) HAp-R (left); and the standard PDF cards for (d) HAp-S, (e) calcium hydroxyapatite, (f) $\beta$-TCP, (g) OCP and (h) DCP (right).

Moreover, no peak was assigned to $\beta$-tricalcium phosphate ( $\beta$-TCP) (PDF 00-0550898); octacalcium phosphate (OCP) (PDF 00-044-0778), nor to calcium pyrophosphate (DCP) (PDF 00-044-0762) were observed (Figure 4 right). In addition, for HAp-R, no other crystalline phase, namely $\mathrm{CaO}$ with $2 \theta$ at $32.2^{\circ}, 37.4^{\circ}$ and $53.9^{\circ}$ (PDF 01-070-4066) or Ca hydroxide with $2 \theta$ at $18.14^{\circ}, 28.7^{\circ}, 34.2^{\circ}$, or $50.8^{\circ}$ (PDF-00-087-0673) were observed. However, it has to be noted that the main XRD peak for $\mathrm{CaO}$ at $2 \theta=32.2^{\circ}$ or $\mathrm{Ca}(\mathrm{OH})_{2}$ at $34.2^{\circ}$, could be hidden by intense peaks of HAp-R between $2 \theta=31^{\circ}$ and $35^{\circ}$.

Thus, it is impossible to distinguish the stoichiometric and non-stoichiometric HAps by $\mathrm{XRD}$, as reported in the literature $[27,30]$.

For the spent catalysts, either washed with water or ethanol, the characteristic peaks of calcium hydroxyapatite (PDF 04-014-8416) were also observed (Figure 5). The XRD results 
revealed that the crystalline structure of recovered HAps, including HAp-Et-1, HAp-W-1, and HAp-Et-Cal-1 remained unchanged after reaction.

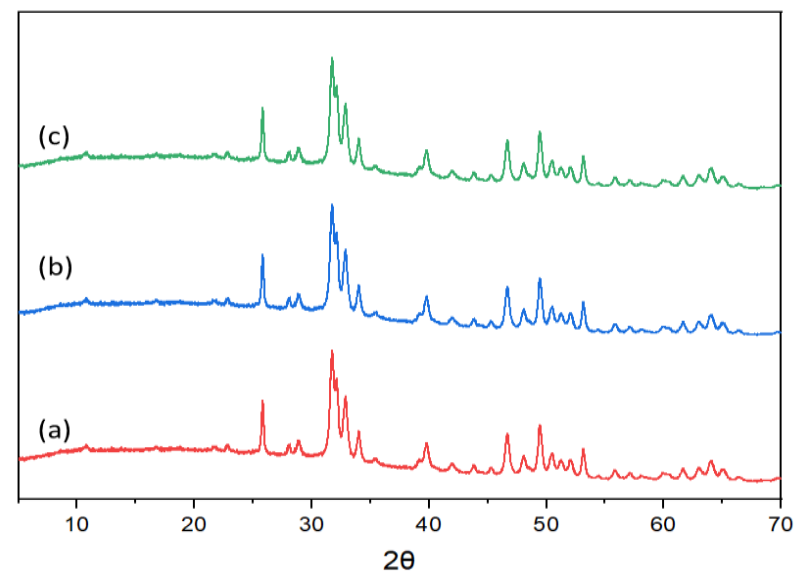

Figure 5. XRD patterns of (a) HAp-Et-1, (b) HAp-W-1, and (c) HAp-Et-Cal-1.

Further, these catalysts were also analyzed by the IR technique to study the carbon bonds, carbon-carbon, and carbon-oxygen bonds, on the spent catalysts.

\subsubsection{IR Analysis}

The structures of the HAps were further studied by IR analysis. For HAp-S, HAp-D, and HAp-R, the IR spectra confirmed the presence of $\mathrm{OH}$ and phosphate groups.

As shown in Figure $6 \mathrm{a}-\mathrm{c}$, the peak at $3572 \mathrm{~cm}^{-1}$ is assigned to the OH groups in HAp structures; and the peaks at $652 \mathrm{~cm}^{-1}, 1084 \mathrm{~cm}^{-1}, 1173 \mathrm{~cm}^{-1}$, and four peaks in the region of 1960 to $2220 \mathrm{~cm}^{-1}$ are assigned to the vibration of $\mathrm{PO}_{4}{ }^{3-}$ in HAps $[27,29,31]$.
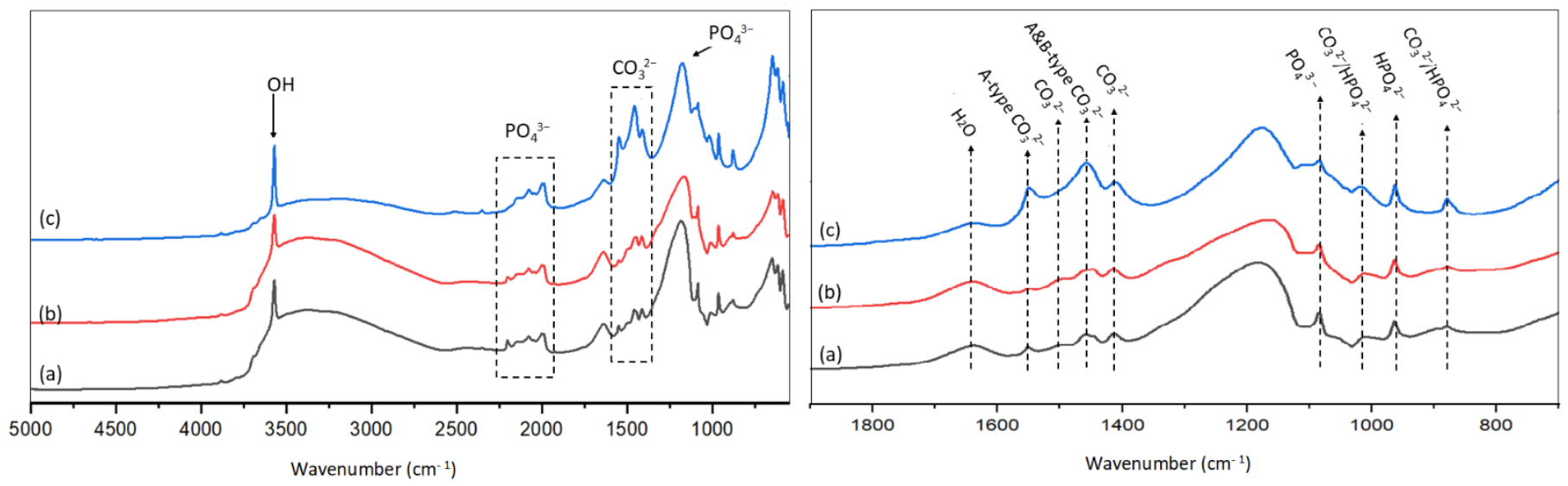

Figure 6. IR spectra for (a) HAp-S, (b) HAp-D, and (c) HAp-R (left) and zooms of the IR spectra for (d) HAp-S, (e) HAp-D and (f) HAp-R (right).

Furthermore, the bands in the regions of $1370 \mathrm{~cm}^{-1}$ and $1580 \mathrm{~cm}^{-1}$ with four peaks at $1413 \mathrm{~cm}^{-1}, 1456 \mathrm{~cm}^{-1}$ (A and B-type), $1500 \mathrm{~cm}^{-1}$, and $1550 \mathrm{~cm}^{-1}$ (A-type) were attributed to carbonate groups $[27,29,32]$. The IR spectra for HAp-D and HAp-S (Figure $6 \mathrm{~d}-\mathrm{f}$ ) showed the presence of carbonated groups in these catalysts, where the intensity of two peaks at $1413 \mathrm{~cm}^{-1}$ and $1456 \mathrm{~cm}^{-1}$ were lower compared to HAp-R (Figure 6f). The presence of $\mathrm{CO}_{3}{ }^{2-}$ in non-carbonated HAps, is consistent with the XPS results (Section 2.3.3) and ICP results (Table 2).

Moreover, three peaks at $878 \mathrm{~cm}^{-1}, 963 \mathrm{~cm}^{-1}$, and $1017 \mathrm{~cm}^{-1}$ assigned to $\mathrm{HPO}_{4}{ }^{2-}[27,29,33]$ were observed for all HAp samples (Figure 6e-f). For the deficient HAp, the presence of 
$\mathrm{HPO}_{4}{ }^{2-}$ was expected. However, for other HAps, the presence of $\mathrm{HPO}_{4}{ }^{2-}$ can be explained by $\mathrm{A}$ and B-type carbonate substitution.

In conclusion, regardless of the $\mathrm{Ca} / \mathrm{P}$ molar ratio in $\mathrm{HAps}$, they all contain $\mathrm{PO}_{4}{ }^{3-}$, $\mathrm{HPO}_{4}{ }^{2-}, \mathrm{CO}_{3}{ }^{2-}$ and $\mathrm{OH}^{-}$groups.

The recovered catalysts, including HAp-Et-1, HAp-W-1, and HAp-W-Cal-1, were also analyzed using IR (Figure $7 \mathrm{~b}-\mathrm{d}$ ). Similarly to HAp-S as the precursor catalyst (Figure 6a), the peaks assigned to $\mathrm{OH}^{-}$, to phosphate groups, and carbonate groups (between $1377 \mathrm{~cm}^{-1}$ and $1580 \mathrm{~cm}^{-1}$ ) were also observed for all the recovered HAps (See Section 2.3.3). However, the intensity of peaks at $1413 \mathrm{~cm}^{-1}, 1456 \mathrm{~cm}^{-1}$ (A and B-type) attributed to carbonate significantly increased for the spent catalysts compared to HAp-S, in the following order: HAp-S $<<$ HAp-Et-1 $<$ HAp-W-1 $<$ HAp-W-Cal-1.

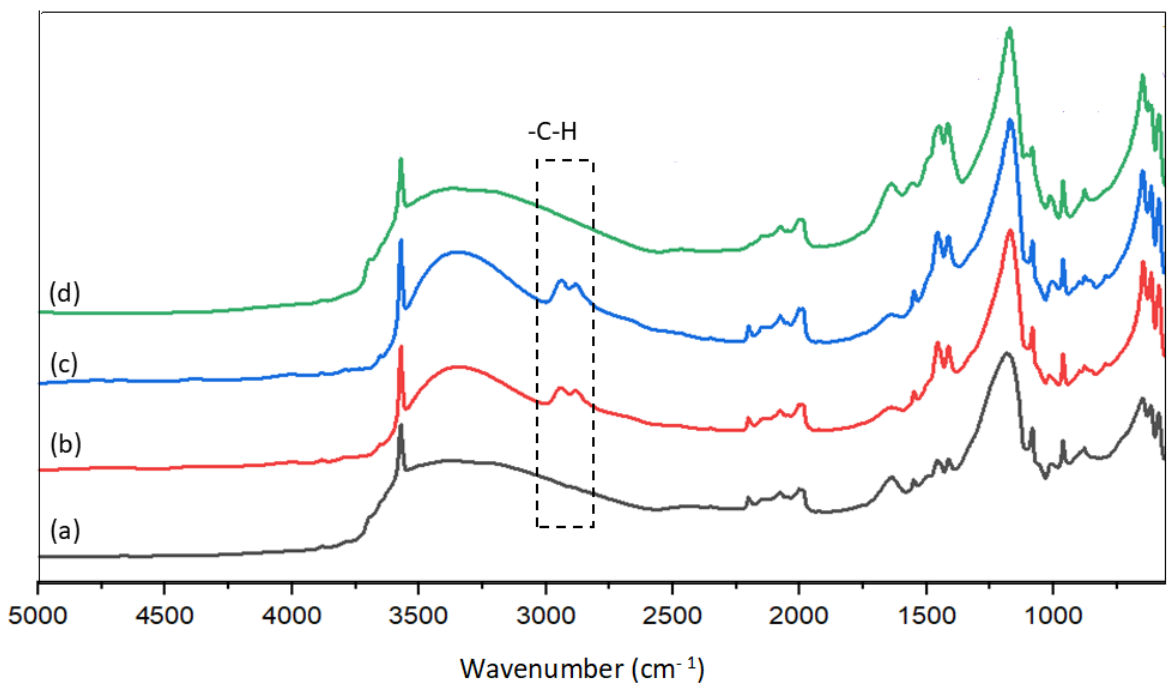

Figure 7. IR spectra for (a) HAp-S before the reaction and spent catalysts (b) HAp-Et-1, (c) HAp-W-1, and (d) HAp-Et-Cal-1.

Besides, two peaks observed at $2880 \mathrm{~cm}^{-1}$ and $2940 \mathrm{~cm}^{-1}$ (Figure $7 \mathrm{~b}-\mathrm{c}$ ) are attributed to the - $\mathrm{C}-\mathrm{H}$ bond on spent HAps. - $\mathrm{CH}$ bonds could form due to the presence of glycerol and/or PGs in the reaction, which is consistent with the decreased specific surface area (Table 2). These peaks disappeared after recalcination of the spent catalyst (HAp-Et-Cal-1) (Figure 7d).

Furthermore, the peak at $3400 \mathrm{~cm}^{-1}\left(3000-3500 \mathrm{~cm}^{-1}\right)$, attributed to the $\mathrm{H}_{2} \mathrm{O}$, became more intense for the non-calcined spent catalysts (Figure $7 \mathrm{~b}-\mathrm{c}$ ), which suggests that the latter became hydrated during the reaction.

\subsubsection{XPS}

XPS analyzed the HAp-D, HAp-S and HAp-R samples to determine their surface compositions, $\mathrm{Ca} / \mathrm{P}$ molar ratio, and oxidation state of the elements. The XPS spectra for these catalysts, showed in Figure 8, indicate the presence of Ca, P, O, and C elements, as was expected.

The peaks at $284.8 \mathrm{eV}, 285.8 \mathrm{eV}$, and $288.6 \mathrm{eV}$ corresponding to $\mathrm{C} 1 \mathrm{~s}$ are attributed to the organic $\mathrm{C}(\mathrm{C}-\mathrm{C}), \mathrm{Ca}-\mathrm{OH}-\mathrm{C}(\mathrm{C}-\mathrm{O})$, and $\mathrm{CO}_{3}$, respectively (not shown), where the peak at $284.8 \mathrm{eV}$ was used to calibrate the spectra. A considerable concentration of carbon contamination on the HAps' surface can originate from the vacuum of the XPS chamber, which is generally known as "adventitious carbon" [34]. 


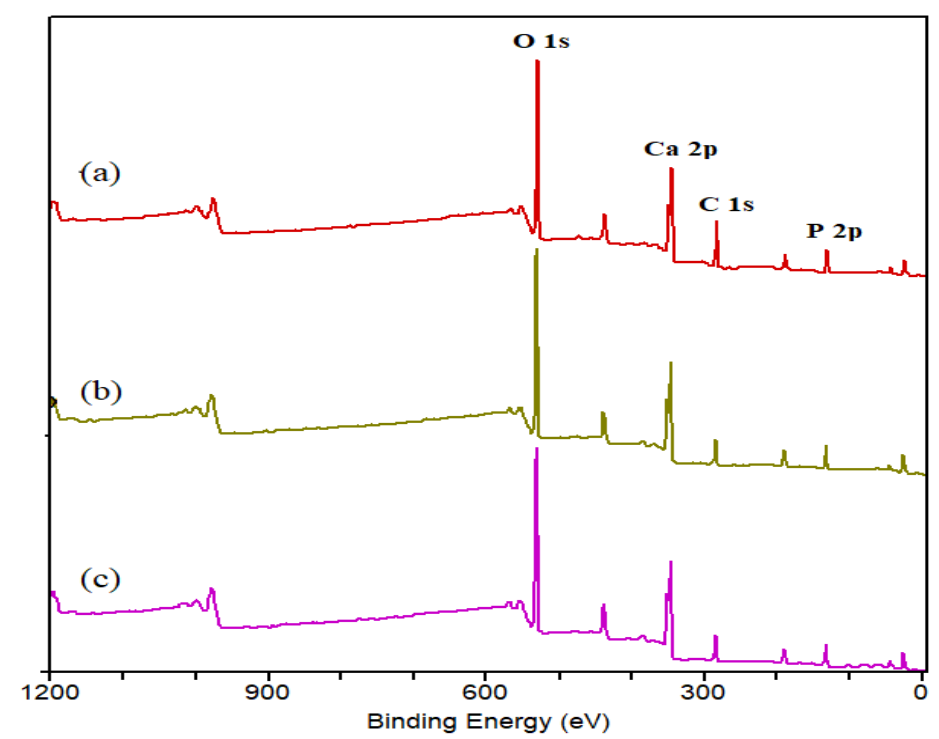

Figure 8. XPS spectra of (a) HAp-D, (b) HAp-S, and (c) HAp-R.

As shown in Figure 9, for HAp-D and HAp-S, a well-defined doublet with two components Ca $2 \mathrm{p}_{1 / 2}(347.4 \mathrm{eV})$ and $\mathrm{Ca} 2 \mathrm{p}_{3 / 2}(350.9 \mathrm{eV})$ is observed, which is attributed to $\mathrm{Ca}$ involved in bonds characteristic of HAps [30,35]. However, the Ca $2 \mathrm{p}$ spectrum of HAp-R suggests that the environment of Ca ions on the surface of HAp-R is not similar to that in HAp-S and HAp-D.
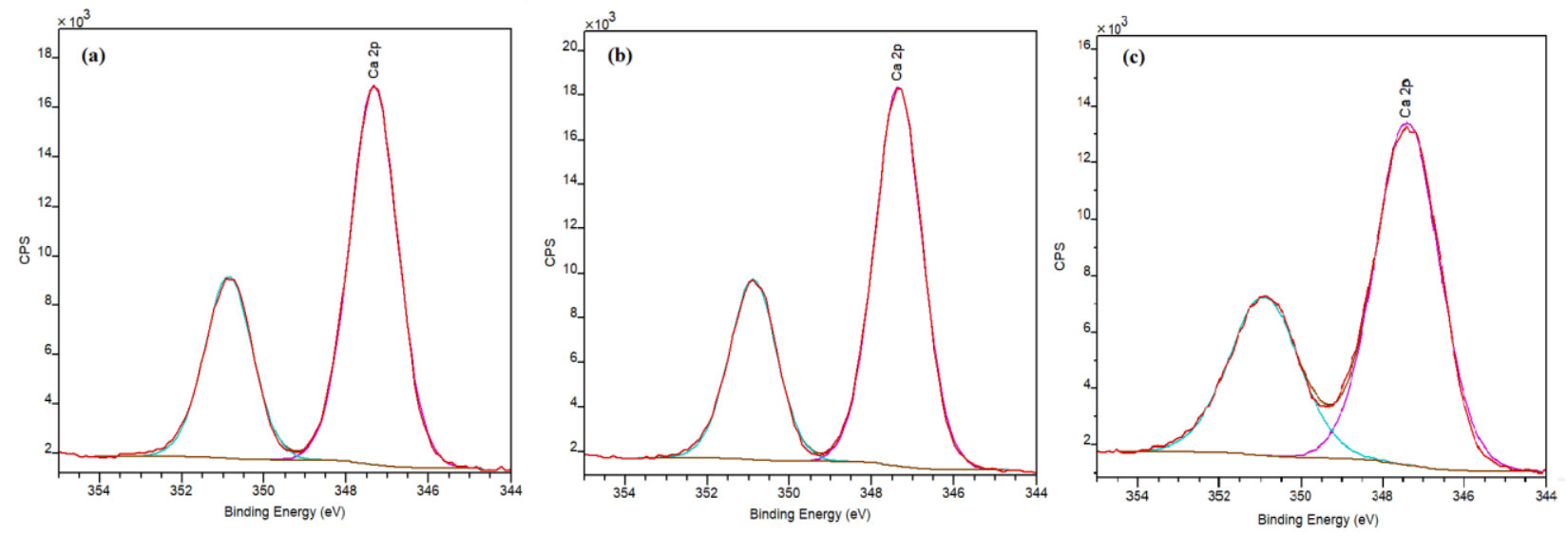

Figure 9. XPS of Ca 2p spectra for (a) HAp-D, (b) HAp-S, and (c) HAp-R.

For all HAps, the $\mathrm{O}$ 1s envelope (not shown) was fitted with two peaks at $531.1 \mathrm{eV}$ and $532.6 \mathrm{eV}$, attributed to O-Ca and O-P (or O-H) in HAps structure, respectively [35,36]. It should be noted that the peak assigned to $\mathrm{O}-\mathrm{C}$ cannot be distinguished in the fitted peaks; however, the presence of carbonate peak $(288.6 \mathrm{eV})$ already confirmed the presence of carbonate on the HAp surface.

Furthermore, the atomic percentages of $\mathrm{Ca}, \mathrm{P}, \mathrm{O}$, and $\mathrm{C}$ are presented in Table 3. These ratios represent the atomic proportion on the surface layer of approximately $10 \mathrm{~nm}$ of HAps' surface. The Ca/P molar ratio for HAp-D, HAp-S, and HAp-R were 1.4, 1.36, and 1.48 , respectively. The lower $\mathrm{Ca} / \mathrm{P}$ ratios obtained on the surface compared to $\mathrm{Ca} / \mathrm{P}$ ratios obtained for the bulk HAps by ICP (Table 2) can be due to the carbonate adsorption on the surface, which caused a change in stoichiometries. This was in agreement with previous studies $[31,36]$ and indicated that Ca species are less exposed on the surface. 
Table 3. Surface chemical compositions (atomic \%) of HAp-D, HAp-S, and HAp-R by XPS analysis.

\begin{tabular}{cccccc}
\hline Catalyst & C 1s (\%) & O 1s (\%) & Ca 2p (\%) & P 2p (\%) & Ca/P (XPS) \\
\hline HAp-D & 35 & 43.8 & 12.4 & 8.8 & 1.40 \\
HAp-S & 21.7 & 51.4 & 15.5 & 11.4 & 1.36 \\
HAp-R & 22.9 & 50.9 & 15.6 & 10.6 & 1.48 \\
\hline
\end{tabular}

\subsubsection{Thermal Analysis}

To study their thermal behaviors, TGA was performed on the non-calcined catalysts, including HAp-D, HAp-S, and HAp-D.

The TGA curve for HAp-D showed a total weight loss of $2.02 \mathrm{wt} . \%$ between room temperature (RT) and $1100{ }^{\circ} \mathrm{C}$. The first weight loss from RT to $140{ }^{\circ} \mathrm{C}$ can be attributed to the release of $\mathrm{H}_{2} \mathrm{O}$ from the sample surface, followed by two steps of mass loss of $0.53 \mathrm{wt} . \%$ and $0.32 \mathrm{wt} . \%$ up to $800{ }^{\circ} \mathrm{C}$ (Figure 10a). The final mass loss of $0.78 \mathrm{wt} . \%$ occurred between $800{ }^{\circ} \mathrm{C}$ and $1100^{\circ} \mathrm{C}$, where an endothermic peak at $957^{\circ} \mathrm{C}$ associated with this weight loss was also observed in the DSC curve.
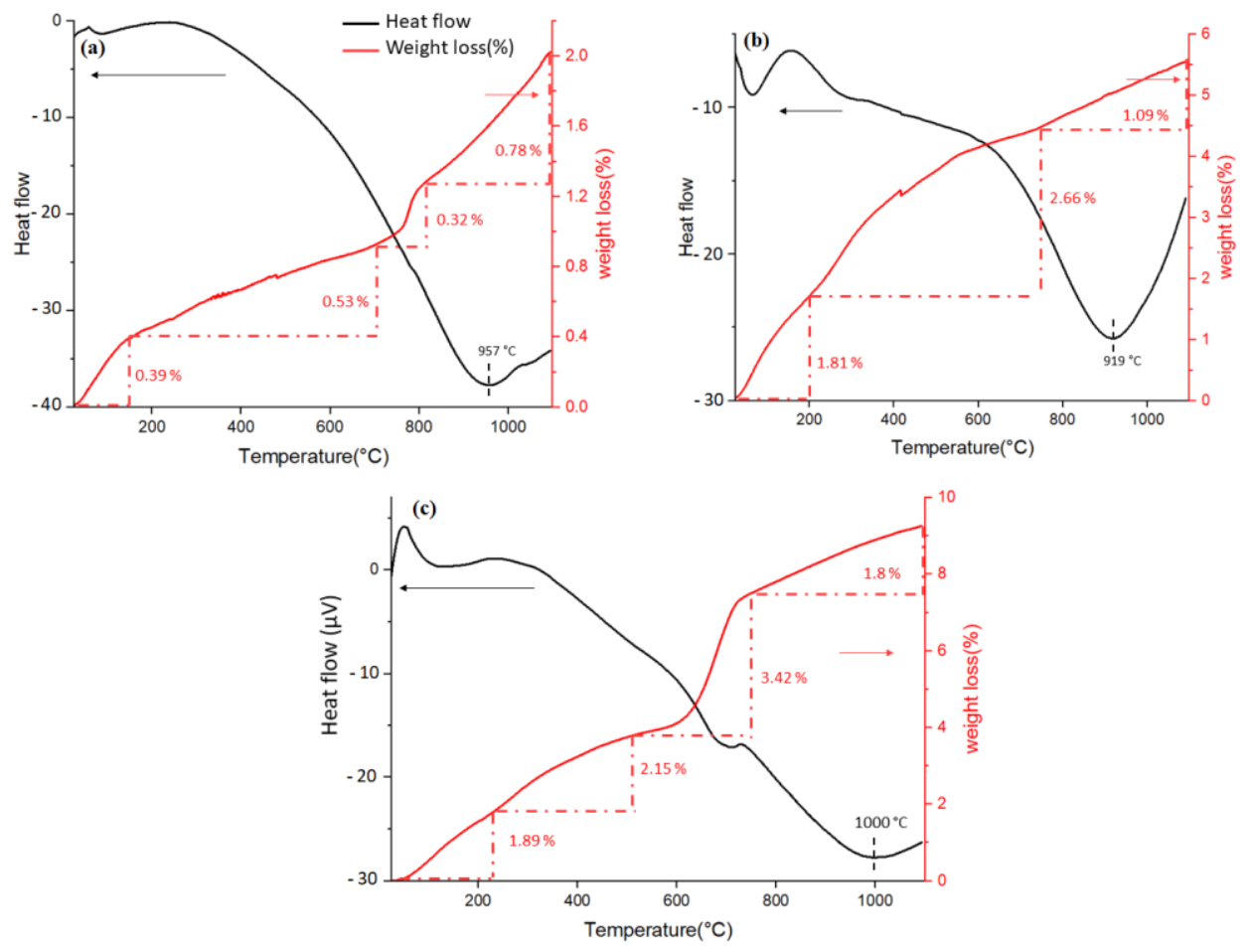

Figure 10. TGA-DSC profiles for non-calcined (a) HAp-D, (b) HAp-S and (c) HAp-R.

Similarly, the TGA curve for HAp-S showed a three steps weight loss with a total loss of $5.56 \mathrm{wt} . \%$ (Figure 10b). The first weight loss $(1.81 \mathrm{wt} . \%)$ from RT to $214{ }^{\circ} \mathrm{C}$, followed by a further weight loss of $2.66 \mathrm{wt} . \%$ up to $743^{\circ} \mathrm{C}$, suggests the release of $\mathrm{H}_{2} \mathrm{O}$ and $\mathrm{CO}_{2}$ from the sample surface. The final weight loss of $1.09 \mathrm{wt} . \%$ with a corresponding endothermic peak at $919^{\circ} \mathrm{C}$ was recorded between $743^{\circ} \mathrm{C}$ and $1100{ }^{\circ} \mathrm{C}$.

For HAp-R, the weight loss was observed in 4 steps. The first two mass losses of $1.89 \mathrm{wt} . \%$ and $2.15 \mathrm{wt} . \%$ were recorded between RT and $587{ }^{\circ} \mathrm{C}$, corresponding to the desorption of $\mathrm{H}_{2} \mathrm{O}$ and $\mathrm{CO}_{2}$ from the surface. The further weight loss of $3.42 \mathrm{wt} . \%$ was recorded between $587^{\circ} \mathrm{C}$ and $745^{\circ} \mathrm{C}$. An endothermic peak at $705^{\circ} \mathrm{C}$, which corresponds to this mass loss, suggests that decarboxylation of HAp-R might have occurred at this temperature range. Finally, HAp-R lost 9.26 wt. $\%$ when heated up to $1100{ }^{\circ} \mathrm{C}$, as shown in Figure 10c. 
For these samples, the large, broad endothermic peak at the range of 900 to $1100{ }^{\circ} \mathrm{C}$ suggests a phase transition of HAps to other apatites such as OCP, DCP, and TCP, meaning that the chosen calcination temperature $\left(700^{\circ} \mathrm{C}\right)$ was optimal.

\section{Discussion}

The results of catalytic tests showed that HAp-D and HAp-S exhibited an excellent selectivity to PG3 (100\%), where the glycerol conversion was $15 \%$. The same catalytic activity for these two catalysts could be due to their similar $\mathrm{Ca} / \mathrm{P}$ bulk molar ratios as measured by ICP-OES (Table 2) or the similar Ca surface content for HAp-S and HAp-D (ca. 36 wt.\%) as obtained by XPS (Table 3). The relatively low glycerol conversion of 15\% can be due to the blockage of the active sites; otherwise, the conversion would still increase with reaction time.

More interestingly, these catalysts also showed good stability during the glycerol polymerization reaction, where $98 \%$ and $99.5 \%$ of HAp-D and HAp-S, respectively, remained as solid in the reaction media after $8 \mathrm{~h}$ of reaction. However, the similar catalytic performances after 8 and $22 \mathrm{~h}$ reaction for the catalysts (Figure 1) suggested that the catalysts deactivated during the reaction.

On the other hand, a higher glycerol conversion was obtained in the presence of HAp$\mathrm{R}(27 \%)$, in the same reaction conditions, where the catalyst showed good selectivity to linear PG2-3 of 88\%. An increase in the glycerol conversion (42\%) with a selectivity of $77 \%$ to PG2-3, after $22 \mathrm{~h}$ reaction, suggested that increased catalytic performance could influence Ca leaching. However, $96.5 \%$ of the catalyst was still solid based on the ICP results.

So far, HAp-D and HAp-S showed better stability compared to HAp-R, while HAp-R exhibited a higher glycerol conversion in the same reaction condition, where the three catalysts were highly selective to PG2-3 and highly stable compared to CaO.

The results of recycling experiments also showed that used HAp-S washed by EtOH (HAp-Et) was successfully reused in the reaction, where it exhibited a glycerol conversion of $15 \%$ after 3 rd run, similar to fresh HAp-S (15\%). In contrast, HAp-W lost its activity when reused for the 2 nd run of reaction (conversion of $7 \%$ vs. 15\%). These results suggested that the catalyst was deactivated upon hydration.

Furthermore, the IR and $\mathrm{C}$ analyses confirmed that the catalysts after reaction became carbonized with the formation of $\mathrm{CO}_{3}{ }^{2-}$ and also contained $-\mathrm{CH}$ groups. In addition, IR analysis showed that the $-\mathrm{CH}$ groups were removed after recalcination of the catalyst (HAp-Et-Cal-1). This result is consistent with $C$ analysis, where the $C$ content decreased from 1.96 to 0.37 wt.\% in HAp-Et -1 and HAp-Et-Cal-1, respectively.

However, the catalytic results proved that $-\mathrm{CH}$ groups did not affect catalytic activity when the regenerated catalyst was reused without any further thermal treatment. However, $-\mathrm{CH}$ groups could convert to $\mathrm{CO}_{3}{ }^{2-}$ under calcination treatment and decrease the activity of the catalyst (HAp-Et-Cal).

As a short conclusion for this part, the XRD patterns for HAps, including HAp-S, HAp-D, and HAp-R confirmed the formation of calcium hydroxyapatite structures, where no other crystalline phase was observed. The XRD results were in good agreement with IR analysis, where the IR spectra exhibited the characteristic peaks of hydroxyapatite, including hydroxyl and phosphate groups for all HAps. In addition to that, the presence of $\mathrm{CO}_{3}{ }^{2-}$ and $\mathrm{HPO}_{4}{ }^{2-}$ were also observed in IR spectra. The IR analysis agreed with $\mathrm{C}$ analysis, where it showed the presence of carbon in HAps.

In addition, the XPS spectra for HAp-D, HAp-S, and HAp-R, confirmed the presence of less Ca exposed on the surface of the catalysts compared to the bulk. This can be due to the presence of various groups, including $\mathrm{CO}_{3}{ }^{2-}$ and $\mathrm{HPO}_{4}{ }^{2-}$ observed by IR, which changed the surface stoichiometries.

Moreover, the thermal analysis showed 2 to $10 \mathrm{wt}$ \% of weight loss for these catalysts, which could be attributed to the release of $\mathrm{H}_{2} \mathrm{O}$ and $\mathrm{CO}_{2}$. The TGA results were also in good agreement with $\mathrm{C}$ analysis, where it confirmed that calcination at $700{ }^{\circ} \mathrm{C}$ partially removed the carbonates in the HAps' structures. Thus, since the results of catalyst characterization 
confirmed the presence of unexpected carbonates in HAps, its effect on the catalyst activity must be studied.

\subsection{Deactivation Mechanisms}

Herein, based on the catalytic performances results and the catalyst characterizations, we focus on the deactivation of the HAps.

In brief, the HAps can be deactivated due to the following reasons:

i. Physical deposition of glycerol and/or reaction products/polymers;

ii. $\mathrm{H}_{2} \mathrm{O}$ interaction with $\mathrm{Ca}^{2+}$ on the surface;

iii. Carbonate formation.

These three hypotheses were examined by performing the following experiments.

\subsubsection{Physical Deactivation}

As aforementioned in Section 2.1, HAp-D and HAp-S were deactivated after $8 \mathrm{~h}$ of reaction. Here, we assumed that the formed PGs could poison the catalyst surface by physical interaction with the catalyst. This hypothesis was examined by performing a reaction with HAp-S as the catalyst in the presence of $3 \mathrm{wt} . \%$ of a PG3 standard. In this case, no glycerol conversion was observed. This result proved that the catalyst's surface was poisoned by PGs (as illustrated in Scheme 1).

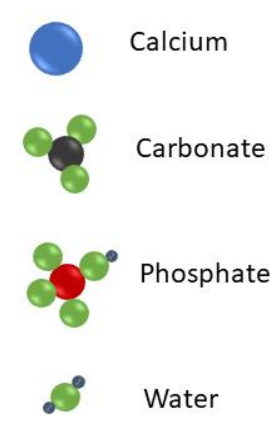

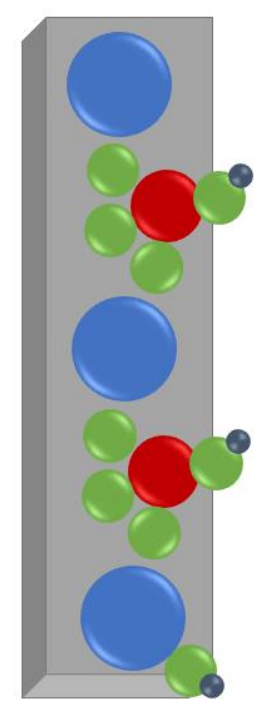

Before reaction

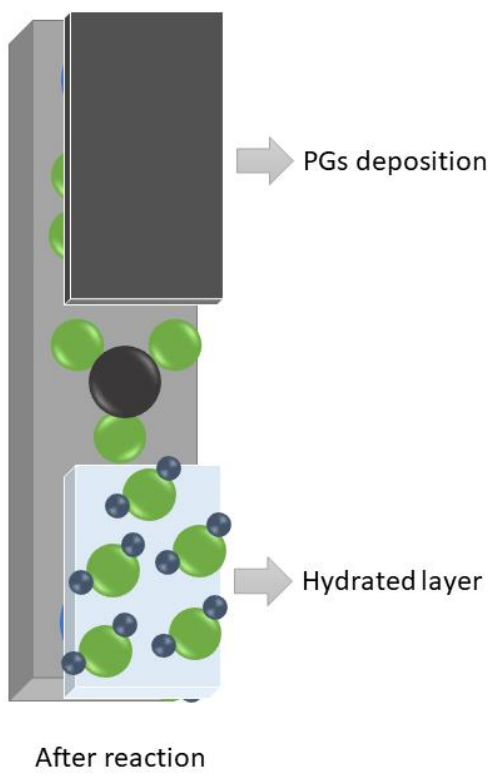

After reaction

Scheme 1. Schematic of HAp' surface before reaction (left) and after reaction upon poisoning by PGs, water, and carbonate (right).

However, as previously observed, when EtOH regenerated the spent catalyst, the PGs layer was washed out, and the catalyst recovered its activity (see Section 2.2).

\subsubsection{Water Deactivation}

This hypothesis of water deactivation was assessed by performing a reaction in the presence of $0.5 \mathrm{wt} . \%$ of extra water in the reaction medium. The results revealed that the catalytic activity dropped to $5 \%$ of glycerol conversion (vs. 15\%). Moreover, when $\mathrm{H}_{2} \mathrm{O}$ was used to regenerate the spent catalyst (see Section 2.2), the catalyst's surface became more hydrated, as shown by the IR analysis (Figure 7), which caused a drop in the activity.

Thus, $\mathrm{H}_{2} \mathrm{O}$ can strongly interact with $\mathrm{Ca}^{2+}$ ions and form a hydrated layer on the surface, including inside the porous network. This phenomenon has already been reported in the literature [37-40]. 


\subsubsection{Carbonate Formation}

In addition to physical deactivations, the catalyst can also be deactivated by carbonate formation. This hypothesis was examined by performing a reaction with HAp-S as the catalyst in the presence of $\mathrm{CO}_{2}$ atmosphere. In this case, very low glycerol conversion $(6 \%)$ was observed. This result proved that the catalyst was deactivated due to the carbonate formation on the surface. In fact, the carbonation probably changed the Ca nature through $\mathrm{CaCO}_{3}$ formation and caused a reduction in catalytic performances. We also previously reported that $\mathrm{CaCO}_{3}$ had a low conversion compare to other catalysts [12].

Moreover, the - $\mathrm{CH}$ bonds on the spent catalysts (Figure $7 \mathrm{~b}, \mathrm{c}$ ) can also deactivate the catalysts upon conversion to carbonate during calcination $\left(\mathrm{CaCO}_{3}\right.$ formation). For instance, the catalytic performances of HAp-Et decreased when it was recalcined under static air (HAp-Et-Cal), where - $\mathrm{CH}$ bonds were removed after thermal treatment and converted to $\mathrm{CO}_{3}$. This phenomenon was confirmed by IR analysis (Figure 7d), where the intensity of carbonate peaks was increased by removing the $-\mathrm{CH}$ peaks.

\section{Materials and Methods}

\subsection{Materials}

$\mathrm{CaO}$ and $\mathrm{Ca}(\mathrm{OH})_{2}$ were purchased from Alfa Aesar. Glycerol (99.5\% purity), $\mathrm{Ca}\left(\mathrm{NO}_{3}\right)_{2} .4 \mathrm{H}_{2} \mathrm{O}$, $\left(\mathrm{NH}_{4}\right) \mathrm{H}_{2} \mathrm{PO}_{4}, \mathrm{NH}_{4} \mathrm{OH}(25-30 \%$ solution), ethanol (99.5\% purity), and were purchased from Sigma-Aldrich. All the chemicals were used as such without any pre-treatment or purification.

\subsection{Catalyst Preparation}

Stoichiometric hydroxyapatite (HAp-S) with a theoretical formula of $\mathrm{Ca}_{10}\left(\mathrm{PO}_{4}\right)_{6}(\mathrm{OH})_{2}$ was synthesized by adding dropwise $60 \mathrm{~mL}$ of an aqueous solution containing $0.033 \mathrm{~mol}$ (7.882 g) of $\mathrm{Ca}\left(\mathrm{NO}_{3}\right)_{2} .4 \mathrm{H}_{2} \mathrm{O}$ to $200 \mathrm{~mL}$ of a $0.0198 \mathrm{~mol}(2.273 \mathrm{~g})$ of $\mathrm{NH}_{4} \mathrm{H}_{2} \mathrm{PO}_{4}$ solution placed under stirring at $70{ }^{\circ} \mathrm{C}$. The $\mathrm{pH}$ of the solution was adjusted to 10 prior to mixing by adding a $25-30 \% \mathrm{NH}_{4} \mathrm{OH}$ solution. The formed precipitate was centrifuged and washed with milli- $\mathrm{Q} \mathrm{H}_{2} \mathrm{O}$ several times before drying at $80{ }^{\circ} \mathrm{C}$ for $48 \mathrm{~h}$. Then, the obtained white solid was calcined at $700{ }^{\circ} \mathrm{C}$ with a ramp of $10^{\circ} \mathrm{C} / \mathrm{min}$ under static air for $4 \mathrm{~h}$.

Deficient hydroxyapatite (HAp-D) with a theoretical formula of $\mathrm{Ca}_{8.7}\left(\mathrm{PO}_{4}\right)_{4.7}\left(\mathrm{HPO}_{4}\right)_{1.3}(\mathrm{OH})_{0.7}$ was synthesized by a method similar to the HAp-S by adding dropwise $60 \mathrm{~mL}$ of an aqueous solution containing $0.033 \mathrm{~mol}(7.882 \mathrm{~g})$ of $\mathrm{Ca}\left(\mathrm{NO}_{3}\right)_{2} .4 \mathrm{H}_{2} \mathrm{O}$ to $200 \mathrm{~mL}$ of a $0.023 \mathrm{~mol}$ (2.64 g) of $\left(\mathrm{NH}_{4}\right) \mathrm{H}_{2} \mathrm{PO}_{4}$ solution.

Ca-rich hydroxyapatite (HAp-R) with the theoretical formula of $\mathrm{Ca}_{11.62}\left(\mathrm{PO}_{4}\right)_{6}(\mathrm{OH})_{2.62}$ was synthesized by an impregnation method similar to methods described previously in the literature [41,42]. To synthesize HAp-R, $4.9 \mathrm{~g}$ of $\mathrm{Ca}(\mathrm{OH})_{2}(0.066 \mathrm{mmol})$ were mixed in $145 \mathrm{~mL}$ of milli-Q $\mathrm{H}_{2} \mathrm{O}$ as a solvent, where the $\mathrm{pH}$ of the initial solution was 12.9. Then, $2.32 \mathrm{~mL}$ of an $85 \%$ of $\mathrm{H}_{3} \mathrm{PO}_{4}$ solution $(0.0341 \mathrm{mmol})$ were added very slowly to adjust the $\mathrm{pH}$ to 4 . The slurry mixture was heated at $80^{\circ} \mathrm{C}$ for $48 \mathrm{~h}$, before washing with milli-Q water for several times and drying at $80{ }^{\circ} \mathrm{C}$ for $72 \mathrm{~h}$ before calcination at $700{ }^{\circ} \mathrm{C}$ with a ramp of $10^{\circ} \mathrm{C} / \mathrm{min}$ for $4 \mathrm{~h}$.

Calcined calcium oxide $(\mathrm{CaO})$ was freshly prepared by performing a high-temperature treatment of calcium nitrate tetrahydrate $\left(\mathrm{Ca}\left(\mathrm{NO}_{3}\right)_{2} \cdot 4 \mathrm{H}_{2} \mathrm{O}\right)$ under static air in a calcination oven, where the nitrate salt was heated to $700{ }^{\circ} \mathrm{C}$ with a ramp of $10{ }^{\circ} \mathrm{C} / \mathrm{min}$ for $2 \mathrm{~h}$.

\subsection{Catalytic Test}

Then, $218 \mathrm{mmol}(20 \mathrm{~g})$ of pure glycerol were placed in a $100 \mathrm{~mL}$ Schlenk tube in the presence of $0.5 \mathrm{~mol} \%$ of catalyst (based on the number of moles of glycerol), including $\mathrm{CaO}$, HAp-S, HAp-D, and HAp-R. The reaction took place at $245{ }^{\circ} \mathrm{C}$ under $\mathrm{N}_{2}$ atmosphere at a stirring rate of $800 \mathrm{rpm}$. After $8 \mathrm{~h}$ of reaction, the catalyst was separated from the reaction medium by centrifugation and washed with ethanol or water. The collected catalysts were characterized after drying under static air at $80^{\circ} \mathrm{C}$ for $4 \mathrm{~h}$. 


\subsection{Glycerol and Polyglycerol Analyses}

The analysis of glycerol was performed using high-performance liquid-phase chromatography (HPLC) equipped with a refractive index (RI) detector. A Bio-Rad (Des Plaines, $\mathrm{IL}$, USA) column ( $300 \mathrm{~mm} \times 7.8 \mathrm{~mm}$ ) was used, and the eluent was a $5 \mathrm{mM} \mathrm{H}_{2} \mathrm{SO}_{4}$ solution fed at $0.5 \mathrm{~mL} / \mathrm{min}$ flowrate. The glycerol conversion was calculated using Equation (1):

Glycerol conversion $(\%)=100 \times \frac{\text { initial mol of glycerol }- \text { mol of unreacted glycerol }}{\text { initial mol of glycerol }}$

PGs analyses were conducted by direct infusion Electrospray Ionization Mass Spectrometry (ESI-MS) in a Waters ESI-MS/MS SYNAPT G2-Si HDMS (High Definition Mass Spectrometer) (USA). ESI was set in the positive ion mode, the heated capillary temperature was $300{ }^{\circ} \mathrm{C}$, the spray voltage $3 \mathrm{kV}$ and the capillary voltage $60 \mathrm{~V}$.

Although quantitative analysis required a pure PG standard for each product, whereas the available standards were a mixture of PGs, a relative PG selectivity was chosen to evaluate the catalysts' performances.

Relative PG selectivity was defined as the ratio of the intensities of the ESI-MS peaks of the di- and tri- glycerol's (PG2-3) or the tetra-, penta- and hexa-glycerol's (PG4+) divided by the sum of the intensities of all the PGs peaks detected, as shown in Equations (2) and (3):

$$
\begin{gathered}
P G_{2-3} \text { selectivity }=100 \times \frac{\text { Sum of } P G 2 \text { and } P G 3 \text { intensities }}{\text { Total } P G \text { s intensities }} \\
P G_{4+} \text { selectivity }=100 \times \frac{\sum_{i=4}^{6} P G_{i}}{\text { Total } P G \text { s intensities }}
\end{gathered}
$$

\subsection{Characterization of Catalyst}

4.5.1. BET

The Brunauer-Emmett-Teller (BET) model serves as the basis for the measurement of the specific surface area of materials. The samples were outgassed at $130{ }^{\circ} \mathrm{C}$ in vacuum for $3 \mathrm{~h}$ before plotting the $\mathrm{N}_{2}$ physisorption isotherms at liquid nitrogen temperature on a TriStar II Plus gas adsorption analyzer (Micromeritics, Norcross, GA, USA). The specific surface areas were evaluated with the BET model over the $P / P_{0}=0.05-0.30$ range.

\subsubsection{XRD}

X-ray diffraction patterns of the solid catalysts were recorded on a D8 Discover X-ray Diffractometer from Bruker using an X-Ray tube with the $\mathrm{Cu}(\mathrm{K} \alpha)$ radiation $(\lambda=1.54060 \AA)$. The diffraction angle $2 \theta$ was taken in the $10-70^{\circ}$ range with steps of $0.01^{\circ}$ per second.

\subsubsection{XPS}

XPS spectra were collected on an Axis UltraDLD Kratos (U.K) spectrometer using the monochromatic $\mathrm{Al} \mathrm{K} \alpha$ radiation $(h v=1486.6 \mathrm{eV})$ as the excitation source. The calibration of the XPS spectra was made using the carbon C1s reference peak at $284.8 \mathrm{eV}$.

\subsubsection{Infrared Spectroscopy (IR)}

Infrared spectroscopy (IR) spectra were recorded on a Fourier transform infrared spectrometer (FTIR), Tensor 37-HTS-XT from Bruker (Mannheim, Germany). An MCT (Mercury-Cadmium-Telluride) photoelectric detector cooled by liquid $\mathrm{N}_{2}$ was used in reflection mode. The spectra were recorded by accumulating 16 scans with a resolution of $4 \mathrm{~cm}^{-1}$.

\subsubsection{Thermal Analyses}

Thermo Gravimetric (TG) and Differential Scanning Calorimetry (DSC) were carried out using a Setaram Labsys instrument (France). Continuous heating was applied from 25 to $1100{ }^{\circ} \mathrm{C}$ with a heating rate of $10{ }^{\circ} \mathrm{C} \mathrm{min}-1$ under $30 \mathrm{ml} / \mathrm{min}$ nitrogen flow. 


\subsubsection{Inductively Coupled Plasma-optic Emission Spectroscopy (ICP-OES)}

These analyses were performed on a 720-ES ICP-OES from Agilent (USA) with axially viewing and simultaneous CCD detection. For liquid samples from reaction media, $20 \mathrm{mg}$ of liquid samples were prepared by diluting them with $4 \mathrm{~mL}$ of milli-Q water. Prior to the analysis of the solid samples, an acid digestion method was applied for the total dissolution of the catalysts before analysis. $10 \mathrm{mg}$ of each sample were digested with $2 \mathrm{~mL}$ of aqua regia $\left(0.5 \mathrm{~mL} \mathrm{HNO}_{3}+1.5 \mathrm{~mL} \mathrm{HCl}\right)$ and mixed under sonification for $15 \mathrm{~min}$ before being kept overnight at ambient temperature before analysis.

\subsubsection{Carbon Analysis}

The carbon amount of HAps catalysts was determined using a Thermo Scientific (Waltham, MA, USA) FlashSmart automated analyzer. The samples were weighted in tin containers and introduced into the combustion reactor. The reactor operated with dynamic flash combustion of the sample at $950{ }^{\circ} \mathrm{C}$, where the $\mathrm{C}$ was detected as $\mathrm{CO}_{2}$. The resultant gases were separated on a packed column heated at $60{ }^{\circ} \mathrm{C}$ in an oven and detected by a thermal conductivity detector (TCD).

\section{Conclusions}

In this paper, the catalytic performances of three calcium-based hydroxyapatites: one stoichiometric, one deficient, and one rich HAps with different theoretical Ca/P molar ratios were assessed for glycerol polymerization. The catalytic tests showed that HAp-D and HAp-S exhibited similar performances, $15 \%$ of conversion with a total selectivity to PG3 $(100 \%)$ at $245^{\circ} \mathrm{C}$ after $8 \mathrm{~h}$ of reaction. HAp-R also exhibited a very good selectivity to linear PG2-3 (88\%) in the same reaction conditions but with a slightly higher activity (27\% glycerol conversion instead of $15 \%$ ).

The same catalytic performances obtained for HAp-D and HAp-S were explained by their similar bulk and surface atomic $\mathrm{Ca} / \mathrm{P}$ ratio, as observed by ICP and XPS. The higher catalytic activity of HAp-R was explained by a higher atomic $\mathrm{Ca} / \mathrm{P}$ ratio than HAp-S and also by the higher amount of Ca leached into the reaction medium (homogeneous contribution). However, this leaching was very low compared to what is observed for $\mathrm{CaO}$.

Further, these catalysts were characterized by XRD, IR, XPS, TGA-DSC, and ICP-OES. As said above, the elemental analysis showed that HAp-D and HAp-S had a close bulk $\mathrm{Ca} / \mathrm{P}$ molar ratio, 1.62 and 1.66, respectively, while HAp-R had a higher $\mathrm{Ca} / \mathrm{P}$ molar ratio of 1.78. However, XRD analysis confirmed that these catalysts had the crystallized structure of Ca hydroxyapatite, despite the difference in their theoretical $\mathrm{Ca} / \mathrm{P}$ ratios. Furthermore, XPS analysis showed the $\mathrm{Ca} / \mathrm{P}$ ratios on the surface of the catalysts were lower than the bulk ones. Hence, less Ca was exposed at the surface of catalysts. Moreover, IR analysis brought new insight into the HAps' structure. The IR analysis confirmed that the HAps contain $\mathrm{CO}_{3}{ }^{2-}$ and $\mathrm{HPO}_{4}{ }^{2-}, \mathrm{PO}_{4}{ }^{3-}$ and $\mathrm{OH}^{-}$groups in their structure. The intensity of carbonate groups in IR was in good agreement with elemental analysis, which was HAp-R (0.8 wt.\%) >> HAp-S (0.111 wt. \%) HAp-D (0.108 wt. \%). The thermal analysis also confirmed that the release of $\mathrm{CO}_{2}$ gradually continued up to $1100^{\circ} \mathrm{C}$ for these catalysts.

Thus far, based on the results, we proposed and examined the three following hypotheses that could explain the catalyst deactivation: (i) Physical deposition of PGs, (ii) water deactivation, and (iii) carbonate formation. Finally, the results confirmed that HAps were mostly deactivated by the presence of products, i.e., "PGs" and water formed by the polymerization reaction.

Thus, it can be concluded that the HAp calcium-based catalysts discussed in this paper are promising solid catalysts for the glycerol polymerization reaction, regarding their high selectivity to PG2-3 and their stability under the reaction conditions.

Author Contributions: N.E. wrote the paper; S.P., F.D. and B.K. led the study, gave advice on the interpretation of results, and revised the paper. All authors have read and agreed to the published version of the manuscript. 
Funding: This research received no external funding.

Acknowledgments: Chevreul Institute (FR 2638), Centrale Lille Institut, Ministère de l'Enseignement Supérieur, de la Recherche et de l'Innovation, Région Hauts-de-France and FEDER are acknowledged for supporting and funding partially this work.

Conflicts of Interest: The authors declare no conflict of interest.

\section{References}

1. Polyglycerol Market Size. 2019. Available online: https://www.grandviewresearch.com/industry-analysis/polyglycerol-market (accessed on 5 May 2020).

2. Ruppert, A.; Meeldijk, J.D.; Kuipers, B.W.M.; Erné, B.H.; Weckhuysen, B.M. Glycerol Etherification over Highly Active CaO-Based Materials: New Mechanistic Aspects and Related Colloidal Particle Formation. Chem.-A Eur. J. 2008, 14, 2016-2024. [CrossRef]

3. Kirby, F.; Nieuwelink, A.-E.; Kuipers, B.W.M.; Kaiser, A.; Bruijnincx, P.C.A.; Weckhuysen, B.M. CaO as Drop-In Colloidal Catalysts for the Synthesis of Higher Polyglycerols. Chem.-A Eur. J. 2015, 21, 5101-5109. [CrossRef]

4. Barros, F.J.S.; Cecilia, J.A.; Moreno-Tost, R.; De Oliveira, M.F.; Rodríguez-Castellón, E.; Luna, F.M.T.; Vieira, R.S. Glycerol Oligomerization Using Low Cost Dolomite Catalyst. Waste Biomass Valorization 2018, 11, 1499-1512. [CrossRef]

5. Gholami, Z.; Abdullah, A.Z. Selective Etherification of Glycerol over Heterogeneous Mixed Oxide Catalyst: Optimization of Reaction Parameters. Chem. Eng. Sci. 2013, 1, 79-86. [CrossRef]

6. Gholami, Z.; Abdullah, A.Z.; Lee, K.T. Heterogeneously catalyzed etherification of glycerol to diglycerol over calcium-lanthanum oxide supported on MCM-41: A heterogeneous basic catalyst. Appl. Catal. A Gen. 2014, 479, 76-86. [CrossRef]

7. Krisnandi, Y.K.; Eckelt, R.; Schneider, M.; Martin, A.; Richter, M. Glycerol Upgrading over Zeolites by Batch-Reactor Liquid-Phase Oligomerization: Heterogeneous versus Homogeneous Reaction. ChemSusChem 2008, 1, 835-844. [CrossRef]

8. Ayoub, M.; Abdullah, A.Z.; Ahmad, M.; Sultana, S. Performance of lithium modified zeolite Y catalyst in solvent-free conversion of glycerol to polyglycerols. J. Taibah Univ. Sci. 2014, 8, 231-235. [CrossRef]

9. Ebadipour, N.; Paul, S.; Katryniok, B.; Dumeignil, F. Alkaline-Based Catalysts for Glycerol Polymerization Reaction: A Review. Catalysts 2020, 10, 1021. [CrossRef]

10. Sayoud, N.; Vigier, K.D.O.; Cucu, T.; De Meulenaer, B.; Fan, Z.; Lai, J.; Clacens, J.-M.; Liebens, A.; Jérôme, F. Homogeneously-acid catalyzed oligomerization of glycerol. Green Chem. 2015, 17, 4307-4314. [CrossRef]

11. Medeiros, M.A.; Araujo, M.H.; Augusti, R.; De Oliveira, L.C.A.; Lago, R.M. Acid-catalyzed oligomerization of glycerol investigated by electrospray ionization mass spectrometry. J. Braz. Chem. Soc. 2009, 20, 1667-1673. [CrossRef]

12. Pour, N.E.; Dumeignil, F.; Katryniok, B.; Delevoye, L.; Revel, B.; Paul, S. Investigating the active phase of Ca-based glycerol polymerization catalysts: On the importance of calcium glycerolate. Mol. Catal. 2021, 507, 111571. [CrossRef]

13. Barros, F.; Moreno-Tost, R.; Cecilia, J.; Ledesma-Muñoz, A.; de Oliveira, L.; Luna, F.M.T.; Vieira, R. Glycerol oligomers production by etherification using calcined eggshell as catalyst. Mol. Catal. 2017, 433, 282-290. [CrossRef]

14. Nieuwelink, A.-E. CaO/CNF for the Oligomerization of Glycerol. Master's Thesis, Department of Chemistry, Utrecht University, Utrecht, The Netherland, 2015.

15. Clacens, J.-M.; Pouilloux, Y.; Barrault, J. Selective etherification of glycerol to polyglycerols over impregnated basic MCM-41 type mesoporous catalysts. Appl. Catal. A Gen. 2002, 227, 181-190. [CrossRef]

16. Chinglenthoiba, C.; Das, A.; Vandana, S. Enhanced biodiesel production from waste cooking palm oil, with NaOH-loaded Calcined fish bones as the catalyst. Environ. Sci. Pollut. Res. 2020, 27, 15925-15930. [CrossRef]

17. Farooq, M.; Ramli, A.; Naeem, A. Biodiesel production from low FFA waste cooking oil using heterogeneous catalyst derived from chicken bones. Renew. Energy 2015, 76, 362-368. [CrossRef]

18. Gupta, J.; Agarwal, M.; Dalai, A.K. Marble slurry derived hydroxyapatite as heterogeneous catalyst for biodiesel production from soybean oil. Can. J. Chem. Eng. 2018, 96, 1873-1880. [CrossRef]

19. Yan, B.; Zhang, Y.; Chen, G.; Shan, R.; Ma, W.; Liu, C. The utilization of hydroxyapatite-supported CaO-CeO 2 catalyst for biodiesel production. Energy Convers. Manag. 2016, 130, 156-164. [CrossRef]

20. Wei, G.; Ma, P.X. Structure and properties of nano-hydroxyapatite/polymer composite scaffolds for bone tissue engineering. Biomaterials 2004, 25, 4749-4757. [CrossRef]

21. Ibrahim, M.; Labaki, M.; Giraudon, J.-M.; Lamonier, J.-F. Hydroxyapatite, a multifunctional material for air, water and soil pollution control: A review. J. Hazard. Mater. 2019, 383, 121139. [CrossRef]

22. Li, X.; Sun, L.; Zou, W.; Cao, P.; Chen, Z.; Tang, C.; Dong, L. Efficient Conversion of Bio-Lactic Acid to 2,3-Pentanedione on Cesium-Doped Hydroxyapatite Catalysts with Balanced Acid-Base Sites. ChemCatChem 2017, 9, 4621-4627. [CrossRef]

23. Matsumura, Y.; Moffat, J.B. Catalytic oxidative coupling of methane over hydroxyapatite modified with lead. Catal. Lett. 1993, 17, 197-204. [CrossRef]

24. Silvester, L.; Lamonier, J.-F.; Lamonier, C.; Capron, M.; Vannier, R.-N.; Mamede, A.-S.; Dumeignil, F. Guerbet Reaction over Strontium-Substituted Hydroxyapatite Catalysts Prepared at Various (Ca+Sr)/P Ratios. ChemCatChem 2016, 9, $2250-2261$. [CrossRef]

25. Ajish, P.; Alex, X. Removal of Protein Aggregates from Biopharmaceutical Preparations Using Calcium Phosphate Salts. WO2011156073A1, 2011. 
26. Raynaud, S.; Champion, E.; Bernache-Assollant, D.; Thomas, P. Calcium phosphate apatites with variable Ca/P atomic ratio I. Synthesis, characterisation and thermal stability of powders. Biomaterials 2001, 23, 1065-1072. [CrossRef]

27. Diallo-Garcia, S. Hydroxyapatites, un Système Basique Atypique Modulable par la Synthèse: Vers L'identification Des sites actifs. Ph.D. Thesis, Université Pierre-et-Marie-Curie, Paris, France, 2012.

28. Ruiz-Aguilar, C.; Olivares, U.; Aguilar-Reyes, E.A.; López-Juárez, R.; Alfonso, I. Characterization of $\beta$-tricalcium phosphate powders synthesized by sol-gel and mechanosynthesis. Boletín Soc. Española Cerámica Vidr. 2018, 57, 213-220. [CrossRef]

29. Koutsopoulos, S. Synthesis and characterization of hydroxyapatite crystals: A review study on the analytical methods. J. Biomed. Mater. Res. 2002, 62, 600-612. [CrossRef]

30. Silvester, L.; Lamonier, J.-F.; Vannier, R.-N.; Lamonier, C.; Capron, M.; Mamede, A.-S.; Pourpoint, F.; Gervasini, A.; Dumeignil, F. Structural, textural and acid-base properties of carbonate-containing hydroxyapatites. J. Mater. Chem. A 2014, 2, 11073-11090. [CrossRef]

31. Silvester, L. Synthesis of Higher Alcohols from Ethanol over Hydroxyapatite-Based Catalysts; Lille University: Lille, France, 2013.

32. Mohammad, N.F.; Amiruddin, N.L.; Saleh, S.S.M.; Taib, M.A.A.; Nasir, N.F.M. Effect of swelling agent on pore properties of mesoporous carbonated hydroxyapatite. J. Phys. Conf. Ser. 2019, 1372. [CrossRef]

33. Von Euw, S.; Wang, Y.; Laurent, G.; Drouet, C.; Babonneau, F.; Nassif, N.; Azaïs, T. Bone mineral: New insights into its chemical composition. Sci. Rep. 2019, 9, 1-11. [CrossRef]

34. Miller, D.J.; Biesinger, M.C.; McIntyre, N.S. Interactions of $\mathrm{CO}_{2}$ and $\mathrm{CO}$ at fractional atmosphere pressures with iron and iron oxide surfaces: One possible mechanism for surface contamination? Surf. Interface Anal. 2002, 33, 299-305. [CrossRef]

35. Gomes, G.C.; Borghi, F.; Ospina, R.; López, E.; Borges, F.; Mello, A. Nd:YAG (532 nm) pulsed laser deposition produces crystalline hydroxyapatite thin coatings at room temperature. Surf. Coatings Technol. 2017, 329, 174-183. [CrossRef]

36. Sheikh, L.; Tripathy, S.; Nayar, S. Biomimetic matrix mediated room temperature synthesis and characterization of nanohydroxyapatite towards targeted drug delivery. RSC Adv. 2016, 6, 62556-62571. [CrossRef]

37. Bolis, V.; Busco, C.; Martra, G.; Bertinetti, L.; Sakhno, Y.; Ugliengo, P.; Chiatti, F.; Corno, M.; Roveri, N. Coordination chemistry of Ca sites at the surface of nanosized hydroxyapatite: Interaction with $\mathrm{H}_{2} \mathrm{O}$ and CO. Philos. Trans. R. Soc. A Math. Phys. Eng. Sci. 2012, 370, 1313-1336. [CrossRef]

38. Prakash, M.; Lemaire, T.; Caruel, M.; Lewerenz, M.; De Leeuw, N.; Di Tommaso, D.; Naili, S. Anisotropic diffusion of water molecules in hydroxyapatite nanopores. Phys. Chem. Miner. 2017, 44, 509-519. [CrossRef]

39. Corno, M.; Rimola, A.; Bolis, V.; Ugliengo, P. Hydroxyapatite as a key biomaterial: Quantum-mechanical simulation of its surfaces in interaction with biomolecules. Phys. Chem. Chem. Phys. 2010, 12, 6309-6329. [CrossRef]

40. Tanaka, H.; Chikazawa, M.; Kandori, K.; Ishikawa, T. Influence of thermal treatment on the structure of calcium hydroxyapatite. Phys. Chem. Chem. Phys. 2000, 2, 2647-2650. [CrossRef]

41. Verwilghen, C.; Rio, S.; Nzihou, A.; Gauthier, D.; Flamant, G.; Sharrock, P.J. Preparation of high specific surface area hydroxyapatite for environmental applications. J. Mater. Sci. 2007, 42, 6062-6066. [CrossRef]

42. Liu, J.; Ye, X.; Wang, H.; Zhu, M.; Wang, B.; Yan, H. The influence of $\mathrm{pH}$ and temperature on the morphology of hydroxyapatite synthesized by hydrothermal method. Ceram. Int. 2003, 29, 629-633. [CrossRef] 